\title{
Analysis of stability parameters in relation to precipitation associated with pre-monsoon thunderstorms over Kolkata, India
}

\author{
H P NAYAK and M MANDAL* \\ Centre for Oceans, Rivers, Atmosphere and Land Sciences, Indian Institute of Technology Kharagpur, \\ Kharagpur 721 302, India \\ ${ }^{*}$ Corresponding author.e-mail: mmandal@coral.iitkgp.ernet.in
}

The upper air RS/RW (Radio Sonde/Radio Wind) observations at Kolkata (22.65N, 88.45E) during premonsoon season March-May, 2005-2012 is used to compute some important dynamic/thermodynamic parameters and are analysed in relation to the precipitation associated with the thunderstorms over Kolkata, India. For this purpose, the pre-monsoon thunderstorms are classified as light precipitation (LP), moderate precipitation (MP) and heavy precipitation (HP) thunderstorms based on the magnitude of associated precipitation. Richardson number in non-uniformly saturated $\left(R_{i}{ }^{*}\right)$ and saturated atmosphere $\left(R_{i}\right)$; vertical shear of horizontal wind in $0-3,0-6$ and 3-7 km atmospheric layers; energy-helicity index (EHI) and vorticity generation parameter (VGP) are considered for the analysis. The instability measured in terms of Richardson number in non-uniformly saturated atmosphere $\left(R_{i}^{*}\right)$ well indicate the occurrence of thunderstorms about 2 hours in advance. Moderate vertical wind shear in lower troposphere $(0-3 \mathrm{~km})$ and weak shear in middle troposphere $(3-7 \mathrm{~km})$ leads to heavy precipitation thunderstorms. The wind shear in 3-7 km atmospheric layers, EHI and VGP are good predictors of precipitation associated with thunderstorm. Lower tropospheric wind shear and Richardson number is a poor discriminator of the three classified thunderstorms.

\section{Introduction}

Thunderstorm is a severe weather phenomenon accompanied by strong winds, lightning, thunder, rainfall and sometime hail. The Gangetic West Bengal gets affected by thunderstorms during the pre-monsoon season (March-May) every year. These thunderstorms cause damage to property and crops; human and animal fatalities, and also aviation hazards. The precipitation associated with the thunderstorms is very useful as it provides temporary relief from the summer heat and supplies much needed water to crops. Because of their high socio-economic impact, thunderstorms are of serious concern to researchers and meteorologists. Extensive research has been carried out in the last nine decades, to investigate various aspects of thunderstorms (Normand 1921; Sohoni 1928; Koteswaram and Srinivasan 1958; Koteswaram and De 1959; Srinivasan et al. 1973; Chatterjee et al. 1995; Sadhukhan and De 1998; Sadhukhan et al. 2000; Mukhopadhyay et al. 2005; Ghosh et al. 2008). Several studies have been conducted to investigate the efficiency of various stability parameters and indices in representing the convective environment leading to the occurrence of

Keywords. Atmospheric instability; stability indices; Richardson number; vertical wind shear; energy-helicity index; vorticity generation parameter. 
thunderstorms (Schultz 1989; Ravi et al. 1999; Kunz 2007; Dhawan et al. 2008; Tyagi et al. 2011). A probabilistic model has also been developed to predict lightning over southeast India using dynamical and thermo-dynamical parameters as predictors (Rajeevan et al. 2012). The model is based on perfect prognostic method and has reasonable skill in predicting lightning events over the reason. But limited studies are conducted on the analysis of stability parameters in relation to the precipitation associated with the thunderstorms. In the present study, several stability parameters have been analysed in relation to the precipitation associated with the pre-monsoon thunderstorms over Kolkata during the period 2005-2012.

Richardson number $\left(R_{i}\right)$ is a useful index in estimating the dynamic instability of the atmosphere that combines thermal instability with vertical wind shear (Shou et al. 2003). It helps in diagnosing the genesis and development of severe weather phenomena, and constructing different stability criteria (Gao and Cao 2007). Zhao et al. (2010) introduced a new Richardson number $\left(R_{i}{ }^{*}\right)$ for non-uniformly saturated atmosphere in which local Brunt Vaisala frequency was computed using generalised potential temperature instead of potential temperature or equivalent potential temperature. Cao et al. (2011) investigated atmospheric stability associated with torrential rain events and heat wave events over north China and concluded that generalised potential temperature $\left(\theta^{*}\right)$ has greater utility in representing dynamic instability in moist weather. In computation of local Brunt Vaisala frequency, equivalent potential temperature $\left(\theta_{e}\right)$ is appropriate for completely saturated atmosphere whereas potential temperature $(\theta)$ is appropriate for dry atmosphere. Since real atmosphere is neither absolutely dry nor entirely saturated, $R_{i}{ }^{*}$ for non-uniformly saturated atmosphere is expected to provide a better measure of instability in real atmosphere. Observations suggest that condensation might occur even when relative humidity is over $78 \%$.

Several previous studies (Malkus 1952; Newton and Newton 1959; Asai 1964; Robe and Emanuel 2001) showed that vertical shear of horizontal wind plays an important role in convective development. Weisman and Klemp (1982) suggested that in a given buoyant environment, weak vertical wind shear generates short-lived single-cell thunderstorms, weak to moderate shear generates multi-cell thunderstorms and moderate to strong shear generates super-cell thunderstorms. Fankhauser $(1971,1988)$ showed that strong vertical wind shear favours strong mean tropospheric wind and hence faster movement of storms. The study also suggested that strong wind shear leads to reduction of precipitation efficiency of the storm.
Schultz (1989) tested seven stability indices for convective development over northeast Colorado and inferred that severe weather threat (SWEAT) index is the best indicator of severe weather. It may be mentioned that among those seven indices SWEAT index was the only index which takes wind shear into account. Rasmussen and Blanchard (1998) showed that energy helicity index (EHI) and vorticity generation parameter (VGP) can well discriminate ordinary, super-cell and tornadic thunderstorms. Savvidou et al. (2010), in their study of extreme and non-extreme thunderstorms over Cyprus illustrated that VGP can be used as a good predictor for classified thunderstorms.

In the present study, analysis of Richardson number, vertical wind shear, EHI and VGP is conducted in relation to the precipitation associated with thunderstorms over Kolkata. General synoptic conditions over the study area are explained in section 2. The upper air observations, radar imageries and information regarding the occurrence of thunderstorm used in the study are discussed in section 3. Mathematical relation used in computation of dynamic/thermodynamic parameters and classification of pre-monsoon thunderstorm is discussed in section 4 . Results are discussed in section 5 and summary of the study is given in section 6 .

\section{Synoptic situation over the Kolkata region during pre-monsoon period}

The Gangetic West Bengal, is frequently affected by thunderstorms in the pre-monsoon season. Although thunderstorm is a mesoscale phenomenon, its occurrence depends on the large scale flow and the prevailing synoptic situations. The Gangetic West Bengal is surrounded by the Bay of Bengal in the south and Chota Nagpur plateau in the west. During the pre-monsoon season, low pressure prevails over Chota Nagpur plateau and the adjoining areas, which gets intensified and extended in the afternoon (Srinivasan et al. 1973). The well marked seasonal high pressure system forms over the Bay of Bengal (Weston 1972). The large scale circulation over the region is characterised by ascending motion over the landmass and descending motion over the adjoining sea. As a result, moisture incursion takes place from the Bay of Bengal along the eastern coast. This is reflected in the large scale circulation pattern with a shallow layer of southerly/southwesterly flow over the Gangetic West Bengal and the adjoining area near the surface and dry westerly aloft. The stable transition layer between the two air streams in which moisture decreases rapidly with height plays an important role in the formation of severe 
thunderstorms. Its presence prevents penetration of convection into the layer above and hence the moisture and warmth in the layer increases. This favours the outbreak of severe thunderstorms (Joseph et al. 2005). The thunderstorms formed under this condition are known as Nor'westers as they come from the northwest. Besides Nor'westers, another type of less intense thunderstorm also occurs over this region, which is termed as sea breeze generated or southerly thunderstorm (Lohar and Pal 1995; Dalal et al. 2012).

\section{Data used}

The 12 UTC upper air RS/RW (Radio Sonde/ Radio Wind) observations at Kolkata (22.65N, $88.45 \mathrm{E}$ ) during pre-monsoon season (March-May) of 2005-2012 are used in computation of dynamic and thermodynamic parameters. Sounding data is taken from Department of Atmospheric Science, Wyoming University (http://weather.uwyo.edu/ upperair/sounding.html). The information regarding the occurrence of thunderstorms over Kolkata is obtained from cyclone detection radar (CDR), Kolkata; STORM Weather Summary (Mohanty et al. 2006, 2007) and weather underground datasets. The radar imagery of the thunderstorm days are obtained from CDR, Kolkata. Accumulated precipitation associated with the thunderstorms is obtained from weather underground using the web link (http://www.wunderground. com/history/airport/VECC/DailyHistory.html).

\section{Methodology}

In this study, some of the important dynamic/ thermodynamic parameters are analysed to investigate their influence on intensity (in terms of associated precipitation) of the pre-monsoon thunderstorms over Kolkata. The pre-monsoon thunderstorms that affected Kolkata during 2005-2012 are considered. A large number of thunderstorms affected Kolkata during the above-mentioned period, but in many instances 12 UTC upper air observations are not available. For the upper air sounding at 12 UTC to be the representative of preconvective environment, the thunderstorms that occurred before 12 UTC are excluded and thunderstorms that occurred between 12 and 18 UTC are considered for analysis. There are 64 such thunderstorms that occurred between 12 and 18 UTC and for which 12 UTC sounding is available. These 64 thunderstorms are classified into thunderstorms with light precipitation (LP), moderate precipitation (MP) and heavy precipitation (HP), depending upon the associated accumulated precipitation (table 1) and have been considered
Table 1. Classification of LP, MP and HP thunderstorms.

\begin{tabular}{lcl}
$\begin{array}{l}\text { No. of } \\
\text { sounding }\end{array}$ & $\begin{array}{c}\text { Precipitation } \\
(\mathrm{mm})\end{array}$ & \multicolumn{1}{c}{$\begin{array}{c}\text { Thunderstorm } \\
\text { classification }\end{array}$} \\
\hline 48 & $0-10$ & Light precipitation (LP) \\
10 & $11-39$ & Moderate precipitation (MP) \\
6 & $\geq 40$ & Heavy precipitation (HP) \\
\hline
\end{tabular}

for analysis. The accumulated precipitation associated with these thunderstorms is shown in figure 1 . The observed upper air profile is vertically interpolated to generate a profile at every $25 \mathrm{hPa}$. The Richardson number for entirely saturated atmosphere and non-uniformly saturated atmosphere; vertical shear of horizontal winds in 0-3, 0-6 and 3-7 km layers; EHI and VGP are computed and analysed for the 64 thunderstorm cases. The mathematical formulae for the computation of the above parameters are given below.

\subsection{Bulk Richardson number}

Following Zhao et al. (2010), Richardson number in an entirely saturated atmosphere $\left(R_{\mathrm{i}}\right)$ and non-uniformly saturated atmosphere $\left(R_{i}^{*}\right)$ are computed using

$$
\begin{aligned}
& R_{i}=N^{2} /\left|\frac{\partial V}{\partial Z}\right|^{2}, \\
& R_{i}^{*}=N^{* 2} /\left|\frac{\partial V}{\partial Z}\right|^{2},
\end{aligned}
$$

where $N$ and $N^{*}$ are Brunt-Vaisala frequency, calculated using equivalent potential temperature $\left(\theta_{e}\right)$ and generalized potential temperature $\left(\theta^{*}\right)$, respectively. The generalised potential temperature defined by Goa et al. (2004) is expressed as $\theta^{*} \equiv \theta \exp \left(L q_{s} Y / C_{p} T\right)$, where $L$ is the latent heat of vaporization, $q_{s}$ is the saturation specific humidity, $C_{p}$ the specific heat capacity at constant pressure, $T$ is the temperature, and $Y$ is a condensation probability function, $\theta$ is potential temperature. The condensation probability function $(Y)$ is defined as $Y=\left(q / q_{s}\right)^{k}$ where $K$ is a constant and $q$ is specific humidity. Based on the earlier studies by Yang et al. (2007) and Zhao et al. (2010), Richardson number $<1$ is taken as measure of instability.

\subsection{Vertical wind shear}

To investigate effect of vertical wind shear [VWS $\left.\left(\mathrm{s}^{-1}\right)\right]$ on precipitation associated with the thunderstorms, the vertical shear of horizontal 


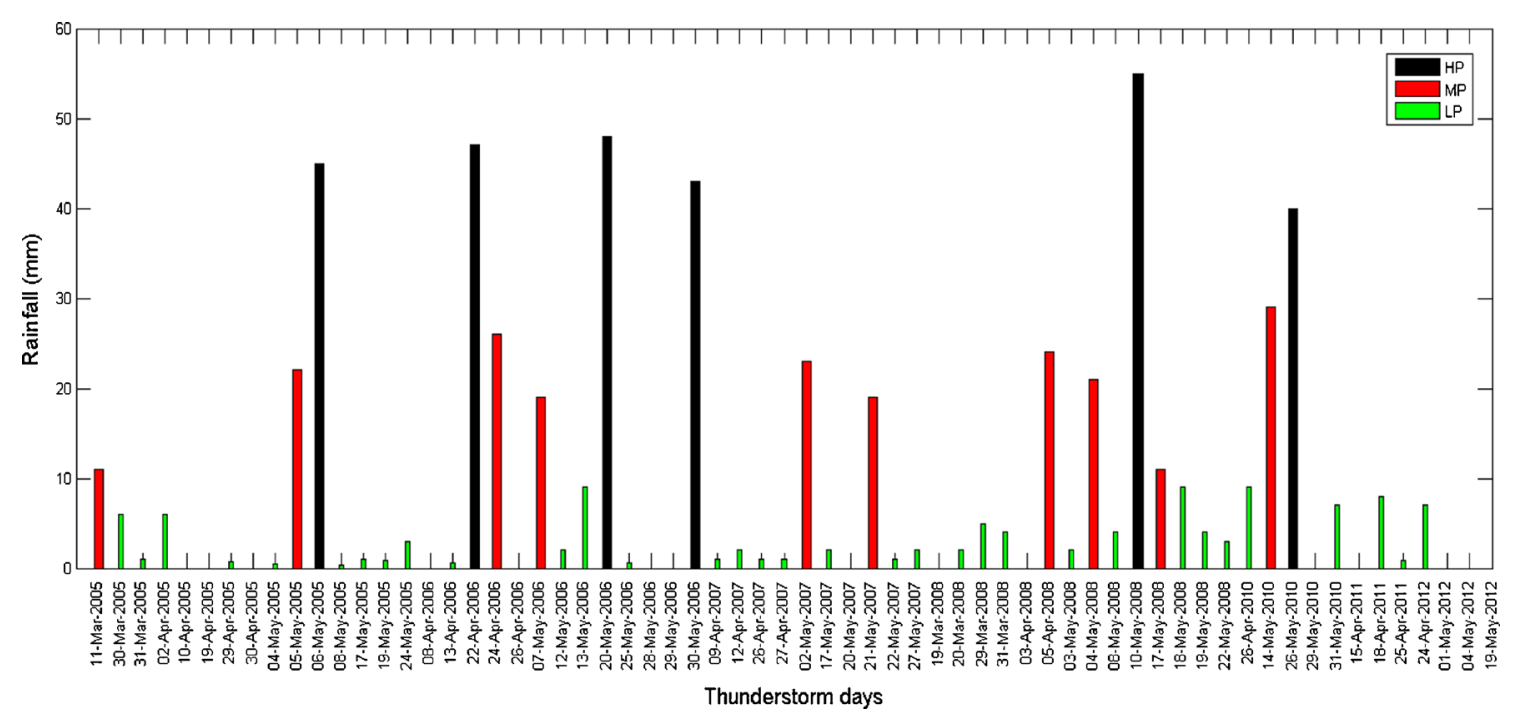

Figure 1. Accumulated precipitation associated with the thunderstorm events considered in the present study.

wind at $0-3,0-6$ and $3-7 \mathrm{~km}$ atmospheric layers are computed using

$$
\operatorname{VWS}\left(\mathrm{s}^{-1}\right)=\frac{\sqrt{\left(u_{2}-u_{1}\right)^{2}+\left(\nu_{2}-\nu_{1}\right)^{2}}}{\left(z_{2}-z_{1}\right)},
$$

where $u_{2}, u_{1}$ are zonal components and $\nu_{2}, \nu_{1}$ are meridional components of wind at heights $z_{2}$, $z_{1}$, respectively. The vertical wind shear at the above-mentioned three layers represents the average of the vertical wind shear in all its sublayers. Weisman and Klemp (1982) studied the effect of wind shear on structure and evolution of convective weather events in mid-latitude. Their study indicates that the vertical wind shear in $0-6 \mathrm{~km}$ atmospheric layer varies in the range of $0-0.008$ $\left(\mathrm{s}^{-1}\right)$ and divided it into weak shear (VWS $<0.003$ $\left.\mathrm{s}^{-1}\right)$, moderate shear $\left(0.003<\mathrm{VWS}<0.005 \mathrm{~s}^{-1}\right)$, and strong shear (VWS $>0.005 \mathrm{~s}^{-1}$ ). Chaudhari et al. (2010), while studying the role of VWS on thunderstorms, reported a similar range of values for VWS at tropical Indian station Minicoy. They also reported higher value of VWS at other tropical stations, viz., Kolkata and Delhi. The present study also indicates higher range of values of VWS at Kolkata. The magnitude of wind shears at each of these three layers is classified as weak, moderate and strong shear based on their statistical distribution. Figure 2 shows the box and whisker diagram of vertical wind shear in the $0-3,0-6$ and 3-7 km atmospheric layers for all 64 cases. It shows that in $90 \%$ cases the wind shear in 0-3 km layer varies in the range of $0.003-0.012$ $\left(\mathrm{s}^{-1}\right)$. Based on this range and their quartile distribution, the wind shear in $0-3 \mathrm{~km}$ atmospheric layer is divided into weak, moderate and strong shear as given in table 2 . In a similar a manner, the wind

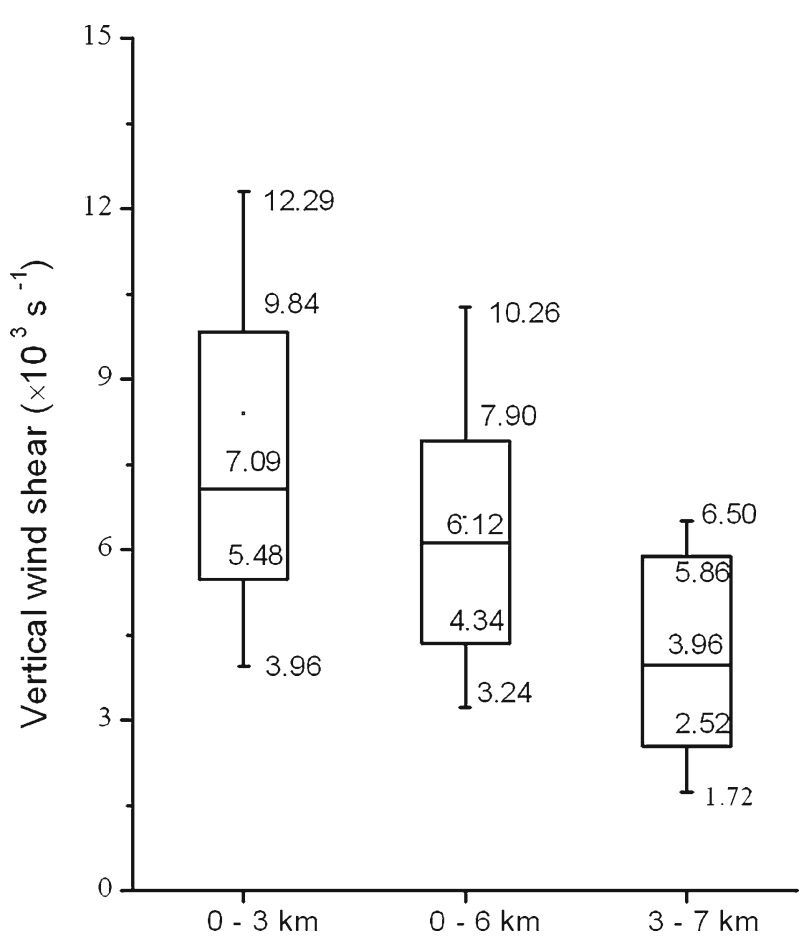

Figure 2. Box-and-Whiskers diagram of $0-3,0-6$ and 3-7 $\mathrm{km}$ vertical wind shear of horizontal wind. The boxes denote 25 th to 75 th percentiles with the middle horizontal bar at the median. The vertical line extends from 10th to 90th percentiles.

shear in $0-6 \mathrm{~km}$ and $3-7 \mathrm{~km}$ atmospheric layers is also divided into weak, moderate and strong shear as shown in table 2 .

\subsection{Energy-helicity index (EHI)}

Energy-helicity is a severe weather index usually used for prediction of super-cell thunderstorms 
and tornadoes. It combines helicity with instability (Hart and Korotky 1991; Davies 1993) and is expressed as:

$$
\mathrm{EHI}=\frac{(\mathrm{CAPE})(\mathrm{SRH})}{1.6 \times 10^{5}}
$$

Higher value of EHI indicates stronger convection. Based on storm relative helicity (SRH) within 0-3 km of the atmosphere, Rasmussen and Blanchard (1998) suggested that EHI $>1.0$ indicates potential for formation of super-cell thunderstorm, whereas EHI > 2.0 indicates high probability of occurrence of the same. In the present study, CAPE in the whole vertical column and $\mathrm{SRH}$ in $0-3 \mathrm{~km}$ of the atmosphere are estimated using RAwinsonde OBservation (RAOB) software and used for computation of EHI.

Table 2. Classification of weak shear, moderate shear and strong shear in $0-3,0-6$ and $3-7 \mathrm{~km}$ of atmospheric layer.

\begin{tabular}{cccc}
\hline & $\begin{array}{c}\text { Weak shear } \\
\left(\times 10^{-\mathbf{3}} \mathrm{s}^{-\mathbf{1}}\right)\end{array}$ & $\begin{array}{c}\text { Moderate shear } \\
\left(\times 10^{-\mathbf{3}} \mathrm{s}^{-\mathbf{1}}\right)\end{array}$ & $\begin{array}{c}\text { Strong shear } \\
\left(\times 10^{-\mathbf{3}} \mathrm{s}^{-\mathbf{1}}\right)\end{array}$ \\
\hline $0-3 \mathrm{~km}$ & $5.5<$ shear & $5.5 \leq$ shear $<9.0$ & shear $\geq 9.0$ \\
$0-6 \mathrm{~km}$ & $4.5<$ shear & $4.5 \leq$ shear $<7.5$ & shear $\geq 7.5$ \\
$3-7 \mathrm{~km}$ & $3.0<$ shear & $3.0 \leq$ shear $<4.5$ & shear $\geq 4.5$ \\
\hline
\end{tabular}

\subsection{Vorticity generation parameter (VGP)}

The vorticity generation parameter (VGP) measures the rate of tilting and stretching of horizontal vorticity in a thunderstorm updraft and is given by:

$$
\mathrm{VGP}=\left[\bar{s}(\mathrm{CAPE})^{1 / 2}\right]
$$

where $\bar{s}$ is mean shear in an atmospheric layer of depth ' $h$ ' and is expressed as:

$$
\bar{s}=\frac{1}{h} \int_{0}^{h} \frac{\partial V}{\partial z} d z .
$$

In the present study, mean shear within $0-3 \mathrm{~km}$ of the atmosphere is used in computation of VGP.

\section{Results and discussion}

The analysis of stability parameter and indices associated with the 64 thunderstorm cases classified into LP, MP and HP thunderstorms are presented in this section. The $R_{i}$ and $R_{i}^{*}$ for 10 non-thunderstorm days are computed to construct the mean profile in a non-convective environment and are compared with that of thunderstorm days.

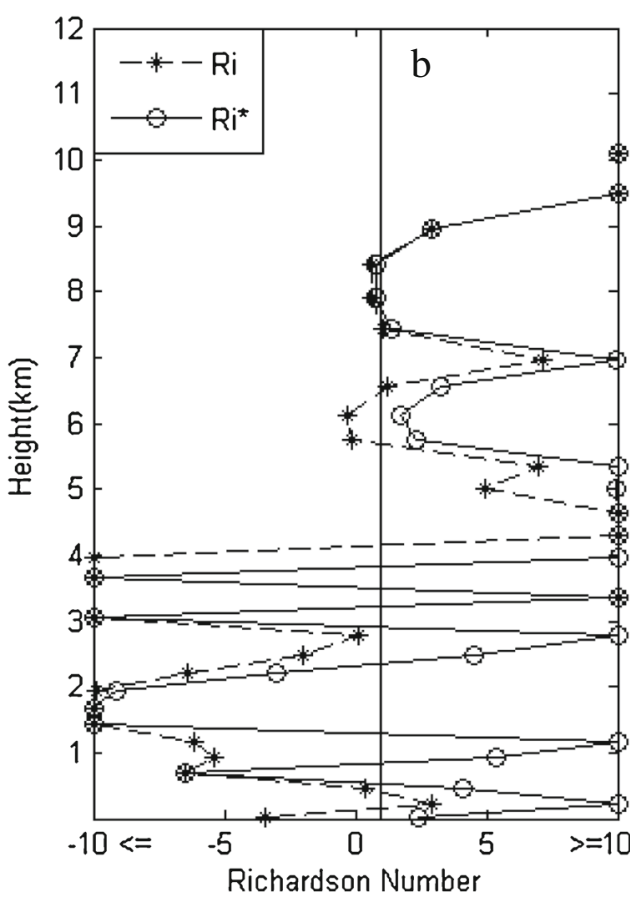

Figure 3. The vertical profile of $R_{i}$ and $R_{i}^{*}$ at 12 UTC (a) on a typical non-thunderstorm day and (b) on thunderstorm day 5th May 2005 (which is approximate average profile of all thunderstorm days considered in the study) over Kolkata, India. The vertical line corresponds to Richardson number $=1$. 


\subsection{Richardson number}

The vertical profile of Richardson number for entirely saturated atmosphere $\left(R_{i}\right)$ and nonuniformly saturated atmosphere $\left(R_{i}^{*}\right)$ at 12 UTC on a typical non-thunderstorm day over Kolkata is shown in figure 3(a). The $R_{i}$ profile shows that the atmosphere is unstable from surface to $5.5 \mathrm{~km}$ and stable above. On the other hand, the vertical profile of $R_{i}^{*}$ shows a stable atmosphere with two thin unstable layers (between $0-0.5$ and $1.2-2.2 \mathrm{~km}$ ). The near surface instability as seen in both $R_{i}$ and $R_{i}^{*}$ may be due to the thermal gradient. Figure 3(b) shows vertical profile of Richardson number at 12 UTC on 5th May 2005, a thunderstorm day over Kolkata which can be taken as a representative of average profile on a thunderstorm day as the profile of most of the thunderstorm days look similar to that of 5 th May 2005. The $R_{i}$ profile shows an unstable layer, $0-4 \mathrm{~km}$ and some instabilities
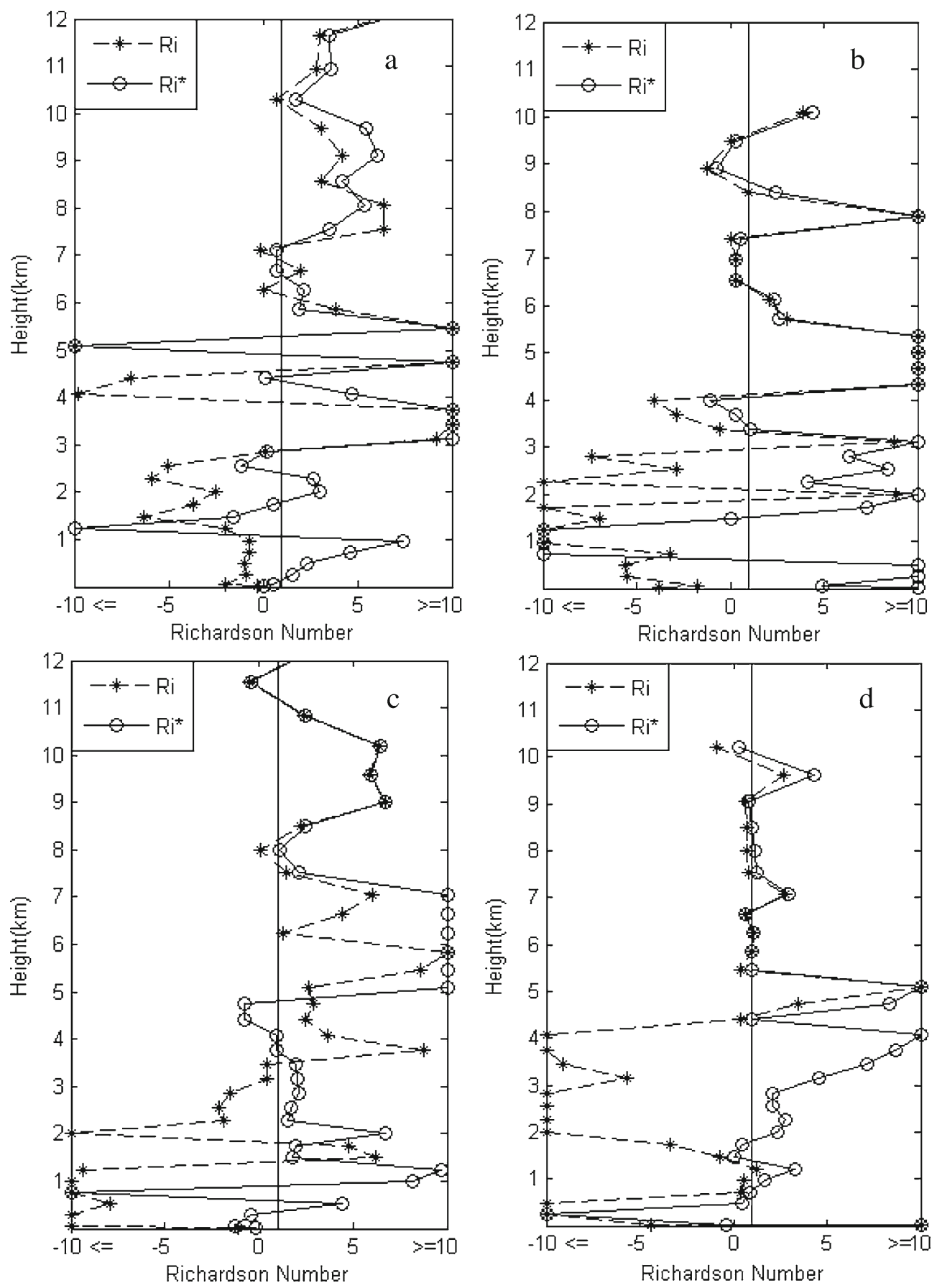

Figure 4. The vertical profile of $R_{i}$ and $R_{i}^{*}$ at 12 UTC on (a) 27 April 2007, (b) 27 May 2007, (c) 26 April 2010 and (d) 18 April 2011 over Kolkata, India. The vertical line corresponds to Richardson number $=1$. 
within the $5.7-8.3 \mathrm{~km}$ layer in the atmosphere. The $R_{i}^{*}$ profile shows instability in the $1.5-3.6$ and 7.8-8.3 km layers of the atmosphere. The deep unstable layer (surface to $5.5 \mathrm{~km}$ ) as seen in the $R_{i}$ profile even on a typical non-thunderstorm day indicates that $R_{i}$ may not be a suitable measure of instability.

Analysis of $R_{i}{ }^{*}$ profile for all the (64) thunderstorm cases indicates that instabilities are usually observed within the $1.5-4$ and $6-11 \mathrm{~km}$ layers. On a particular thunderstorm day, instabilities may be present either in both the layers or in one of the layers. In $81 \%$ cases such instabilities are observed. In $68.25 \%$ cases instability is observed within $1.5-4 \mathrm{~km}$, in $35.08 \%$ cases instability is observed within $6-11 \mathrm{~km}$ and in $19.04 \%$ cases instabilities are observed in both the layers. It may be mentioned here that in $10.8 \%$ cases the sounding data is not available beyond $6 \mathrm{~km}$ and instability in the $6-11 \mathrm{~km}$ layer could not be investigated. It is also observed that clouds have high vertical extent (in the range of $10-16 \mathrm{~km}$ ) if there is instability within the $6-11 \mathrm{~km}$ atmospheric layer favouring the convective development. The lower level $(1.5-4 \mathrm{~km})$ instability in terms of $R_{i}^{*}$ is a good indicator of thunderstorm occurrence as it can explain the occurrence of $68.25 \%$ thunderstorms. The Richardson number for classified LP, $\mathrm{MP}$ and HP thunderstorm cases is discussed below.

\subsubsection{LP thunderstorm cases}

As shown in table 1 , there were 48 thunderstorm cases with low precipitation. Four such cases, 27
April 2007, 27 May 2007, 26 April 2010 and 18 April 2011 are discussed in detail. The precipitations associated with these four cases are 1,2, 9 and $8 \mathrm{~mm}$, respectively. The vertical profile of Richardson number for completely saturated atmosphere $\left(R_{i}\right)$ and non-uniformly saturated atmosphere $\left(R_{i}^{*}\right)$ at 12 UTC on 27 April 2007, 27 May 2007, 26 April 2010 and 18 April 2011 are shown in figure $4(\mathrm{a}-\mathrm{d})$. The $R_{i}$ profile of 27 April 2007 (figure 4a) shows unstable atmosphere from surface to $3 \mathrm{~km}$ and weak unstable layer within 4$7 \mathrm{~km}$ of the atmosphere. Analysis of $R_{i}^{*}$ profile, shows instability in the $1-3$ and in $4.3-7 \mathrm{~km}$ layers of atmosphere. The DWR reflectivity at 13:10 UTC of 27 April 2007 is shown in figure 5(a). It shows a squall line passing over Kolkata region with vertical extent $12 \mathrm{~km}$ and the maximum reflectivity in the range of $49-57 \mathrm{dBZ}$. But the precipitation associated with the thunderstorm event is less $(1 \mathrm{~mm})$. In this case, in addition to atmospheric instability which led to the formation of deep convective clouds, the dynamical parameter may have played an important role resulting in less precipitation over the region. $R_{i}$ profile of 27 May 2007 (figure $4 \mathrm{~b}$ ) indicates that the atmosphere is unstable from the surface to $4 \mathrm{~km}$ and $6.5-9.5 \mathrm{~km}$ layers. $R_{i}^{*}$ profile shows instability in the $0.7-1.5$, $3.5-4$ and $6.5-9.5 \mathrm{~km}$ atmospheric layers. The DWR reflectivity at 14:44 UTC of 27 May 2007 is shown in figure 5(b). It shows a large squall line passing over Kolkata with maximum reflectivity in the range of $46-52 \mathrm{dBZ}$. It also shows that the vertical extent of the cloud is $11 \mathrm{~km}$ (approx). On 26 April 2010, the $R_{i}$ profile (figure 4c) shows unstable atmosphere from surface to $3.5 \mathrm{~km}$. The
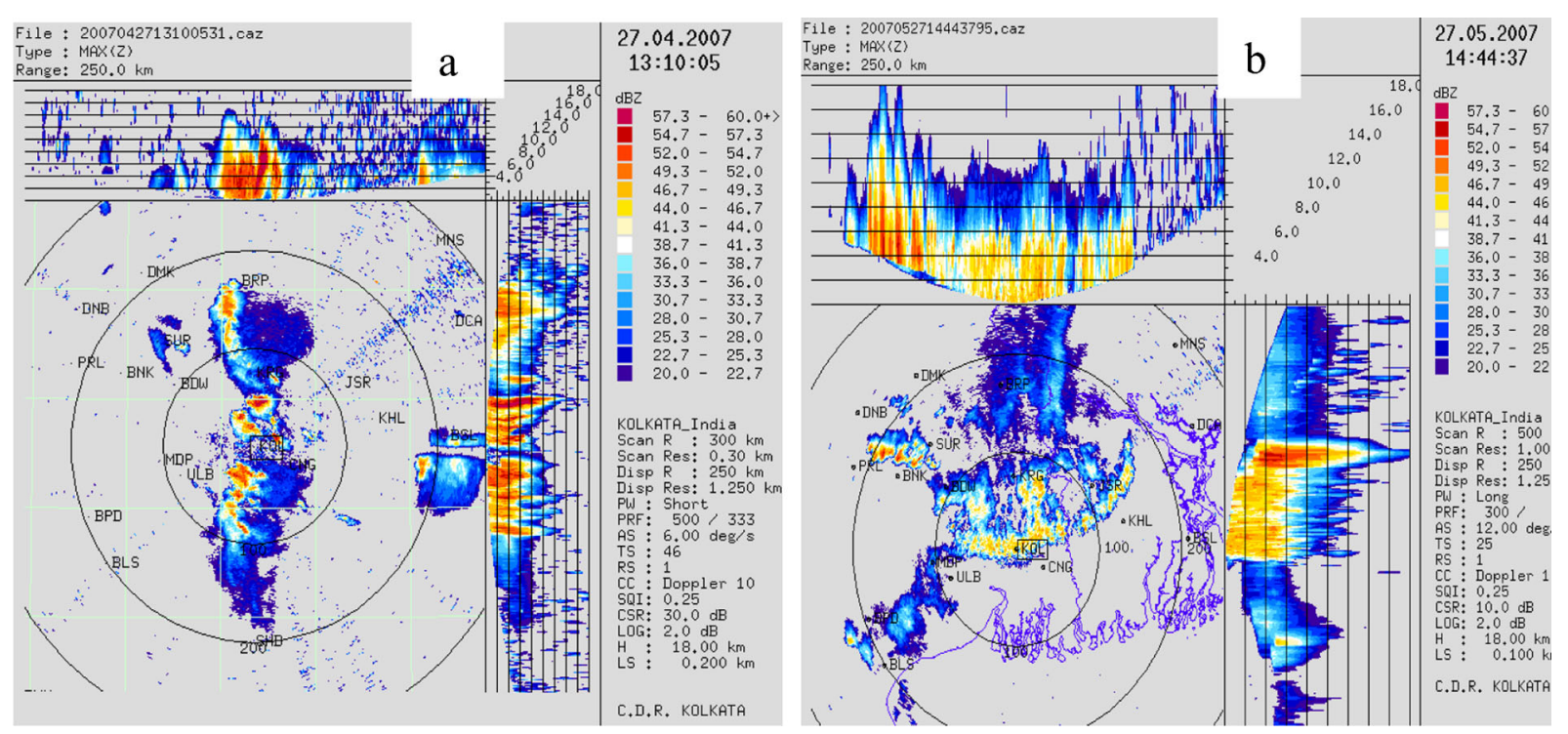

Figure 5. DWR reflectivity (MaxZ) of thunderstorm event (a) at 13.10 UTC 27 April 2007 and (b) at 14.44 UTC on 27 May 2007 over Kolkata, India. 
$R_{i}{ }^{*}$ profile indicates significant instability in the $3.5-4.5 \mathrm{~km}$ layer of the atmosphere. Weak upper tropospheric instabilities are also observed in both $R_{i}$ and $R_{i}^{*}$ profiles. DWR reflectivity (figure not presented) of 26 April 2010 shows that the thunderstorm passed over Kolkata around 14:21 UTC and it was less intense compared to the previous two cases. The $R_{i}$ profile at 12 UTC on 18 April 2011 (figure $4 \mathrm{~d}$ ) shows that the atmosphere is unstable from surface to $10 \mathrm{~km}$. In the $R_{i}^{*}$ profile, instabilities are observed in the atmospheric layer, surface to $1.7 \mathrm{~km}$ and also within the layer $5.8-10 \mathrm{~km}$. DWR reflectivity (figure not presented) of 18 April 2011 shows that the thunderstorm passed over Kolkata around 18:00 UTC and it was more intense compared to the previous cases. DWR reflectivity indicates that if there are instabilities in the middle and upper troposphere then the vertical extent of
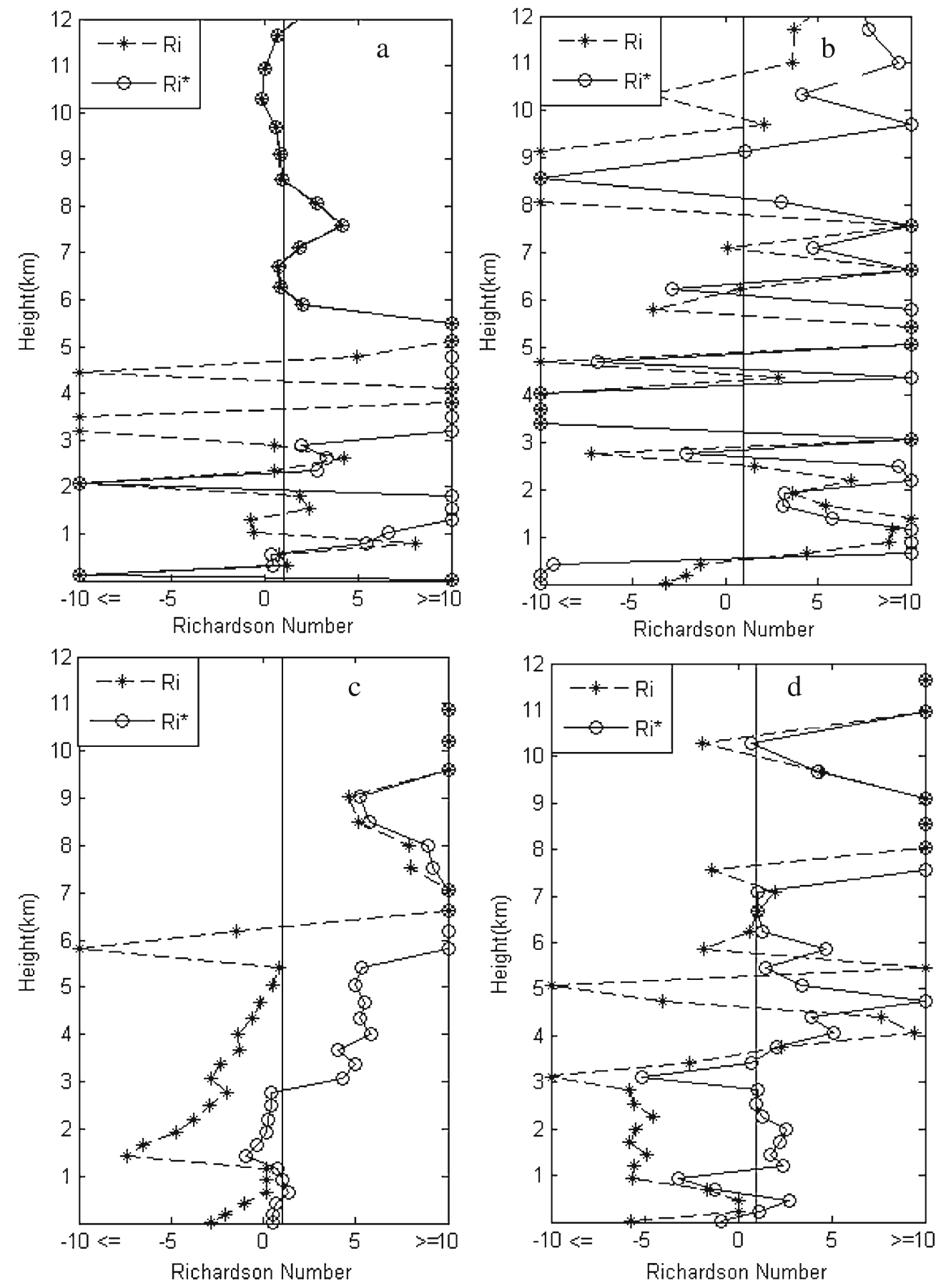

Figure 6. The vertical profile of $R_{i}$ and $R_{i}^{*}$ at 12 UTC on (a) 24 April 2006, (b) 21 May 2007, (c) 17 May 2008 and (d) 14 May 2010. The vertical line corresponds to Richardson number $=1$. 
the cloud is in the range of $11-14 \mathrm{~km}$ and deeper the level of instability deeper is the cloud. It may be noted that the presence of deep clouds does not ensure higher magnitude of precipitation. Zhao et al. (2010) simulated two heavy rainfall events over north China and suggested that thin layer of instability (in terms of $R_{i}^{*}$ ) results in very weak precipitation or no precipitation. However, the present study shows that even the thick layer of the instability (measured in terms of $R_{i}^{*}$ ) is associated with weak precipitation.

\subsubsection{MP thunderstorm cases}

There were 10 thunderstorm cases with moderate precipitation within the study period. Four such cases, 24 April 2006, 21 May 2007, 17 May 2008 and 14 May 2010 are considered for detailed discussion. The precipitations associated with these four cases are 26, 19, 11 and $29 \mathrm{~mm}$, respectively. The vertical profile of Richardson number for completely saturated atmosphere $\left(R_{i}\right)$ and non-uniformly saturated atmosphere $\left(R_{i}^{*}\right)$ at 12 UTC on 24 April 2006, 21 May 2007, 17 May 2008 and 14 May 2010 are shown in figure 6(a-d). On 24 April 2006 (figure 6a), deep layer of instability within the 6$12 \mathrm{~km}$ of atmospheric layer is observed in both $R_{i}$ and $R_{i}^{*}$ profile. The $R_{i}$ and $R_{i}^{*}$ profiles were found to coincide above $5 \mathrm{~km}$ (approx). In saturated atmosphere $\theta^{*}=\theta_{e}$ and hence $R_{i}^{*}=R_{i}$. In this case, the sounding is available $87 \mathrm{~min}-$ utes before the occurrence of the thunderstorm. The atmosphere above $5 \mathrm{~km}$ might be saturated resulting in coincidence of two profiles. The DWR reflectivity at 13:27 UTC of 24 April 2006 thunderstorm event is shown in figure 7 (a). The maximum reflectivity in the range of 49-57 dBZ with vertical extent of the cloud is up to $12 \mathrm{~km}$. Instability due to $R_{i}^{*}$ agrees well with DWR reflectivity. The $R_{i}$ and $R_{i}^{*}$ profile of 21 May 2007 (figure 6b) thunderstorm event shows an unstable atmosphere with similar Richardson number profile. In this case, the thunderstorm was initiated at the time of observation and that may be the reason for both the profiles being identical. DWR reflectivity at 8:06 UTC of 21 May 2007 shows deep cloud bands approaching Kolkata with high vertical extent (figure 7b). It may be noted that Radar reflectivity during the occurrence of the thunderstorm was not available. The $R_{i}$ profile of 17 May 2008 (figure 6c) indicates that the atmosphere is unstable from surface to $6 \mathrm{~km}$ and stable above $6 \mathrm{~km} . R_{i}{ }^{*}$ profile shows unstable atmosphere from surface to $3 \mathrm{~km}$ (approx.) and stable profile observed beyond $3 \mathrm{~km}$ of the atmosphere. $R_{i}$ profile of 14 May 2010 (figure 6d) shows unstable atmosphere from surface to $3.5 \mathrm{~km}$ and $4.7-7.5 \mathrm{~km}$ whereas $R_{i}^{*}$ profile shows instabilities in the $0.6-1.0,2.5-3.5$ and $6.6^{-}$ $7.1 \mathrm{~km}$ atmospheric layer. In this case, sounding is available $5 \mathrm{~h}$ before the occurrence of the thunderstorm. No significant unstable layer is observed in middle or upper troposphere. The lower tropospheric instability observed in the $R_{i}^{*}$ profile might have intensified in due course and formed clouds with high vertical extent. The DWR reflectivity (figure not presented) of 17 May 2008 and 14 May 2010 shows similar features to that of the previous cases.
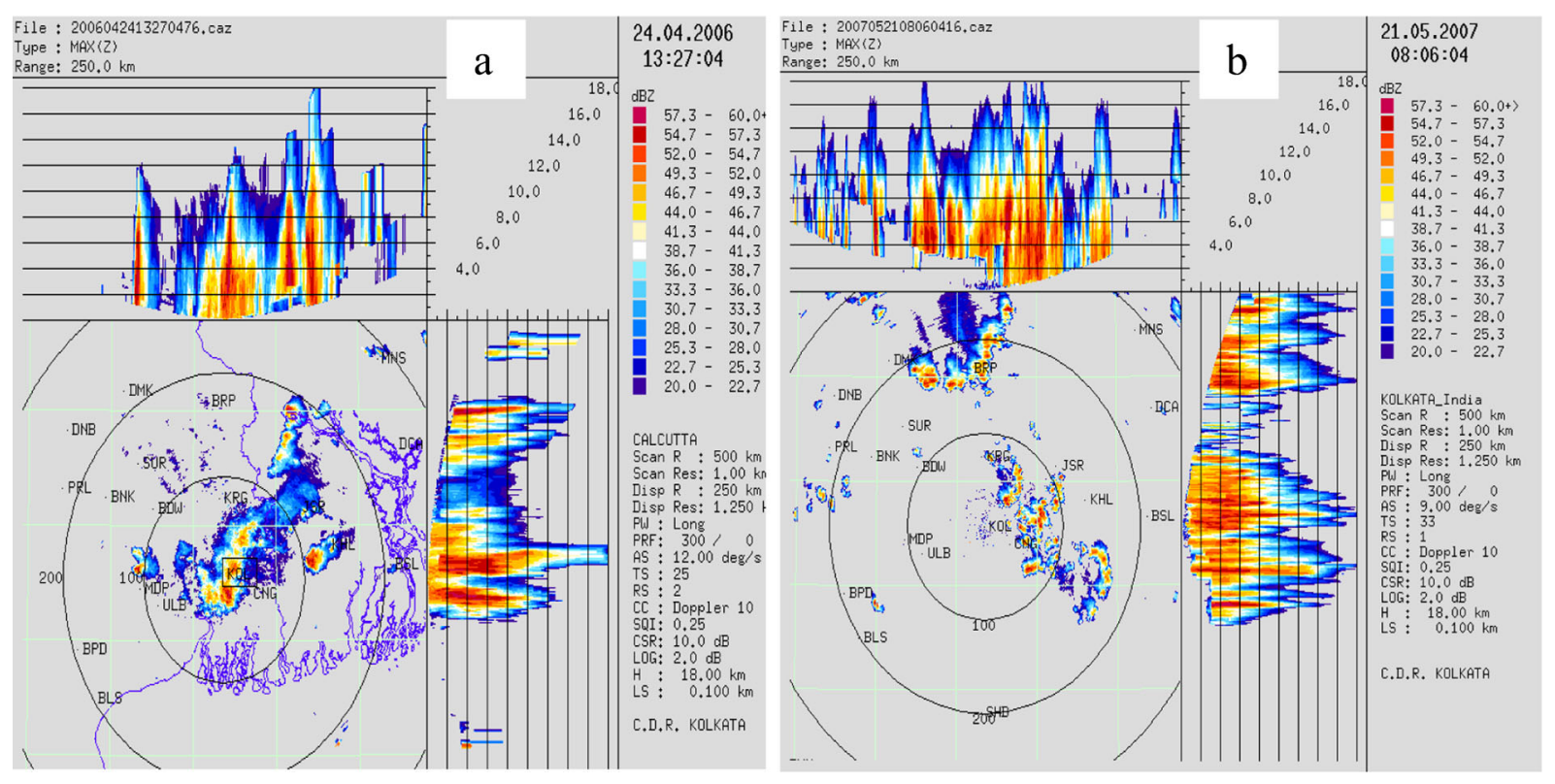

Figure 7. DWR reflectivity (MaxZ) of thunderstorm event (a) at 13.27 UTC on 24 April 2006 and (b) at 08:06 UTC on 21 May 2007 over Kolkata, India. 

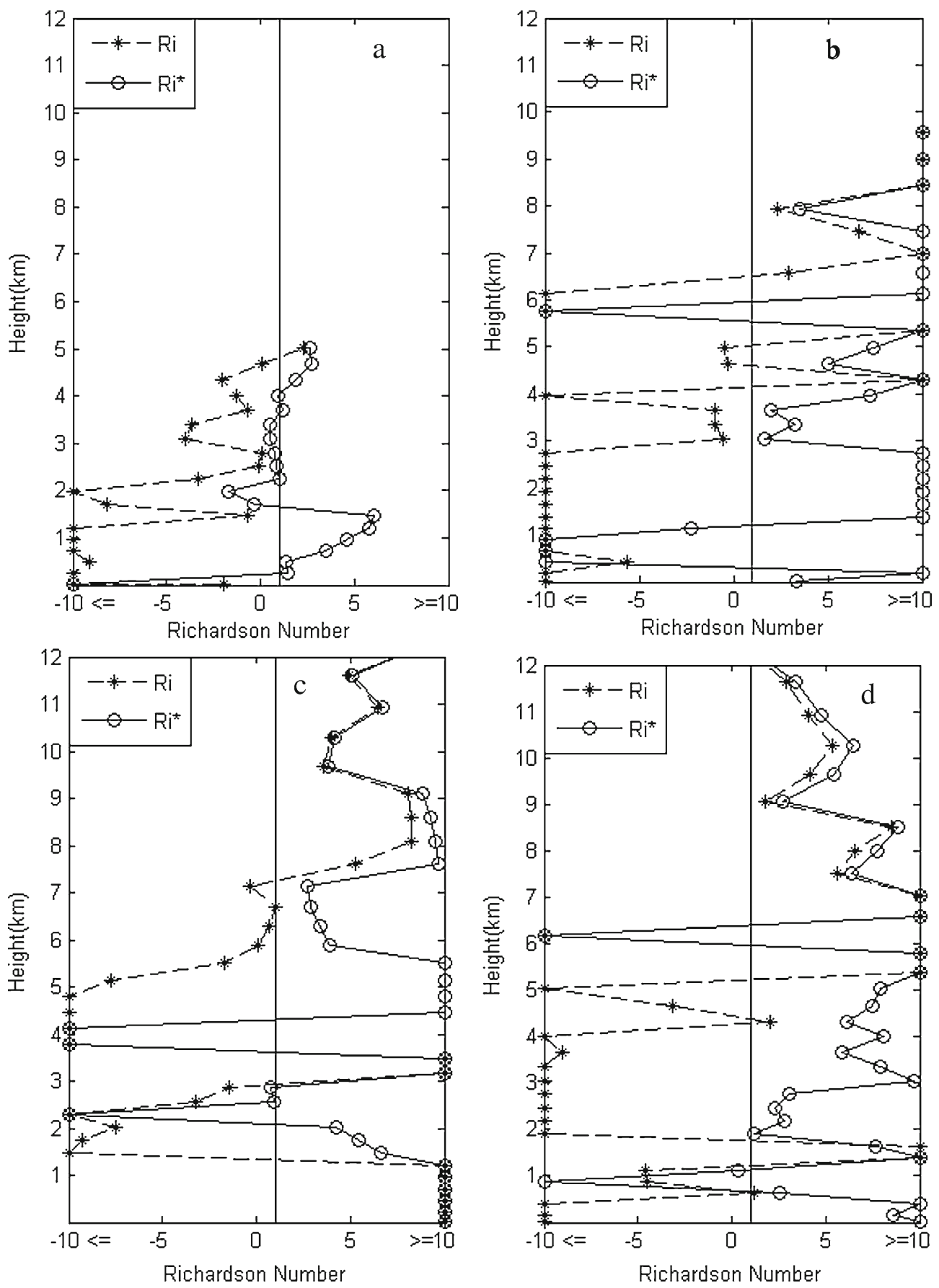

Figure 8. The vertical profile of $R_{i}$ and $R_{i}^{*}$ at 12 UTC on (a) 22 April 2006, (b) 30 May 2006, (c) 10 May 2008 and (d) 26 May 2010. The vertical line corresponds to Richardson number $=1$.

\subsubsection{HP thunderstorm cases}

There were six heavy precipitation thunderstorms of which four cases, 22 April 2006, 30 May 2006, 10 May 2008, and 26 May 2010 are considered for detailed discussion. The precipitations associated with the above cases are $47,43,55$, and 40 $\mathrm{mm}$, respectively. The vertical profiles of $R_{i}$ and $R_{i}^{*}$ at 12 UTC of these four thunderstorm events are shown in figure 8(a-d). $R_{i}$ profile of 22 April 2006 (figure 8a) indicates that the atmosphere is unstable from surface to $4.6 \mathrm{~km}$. The profile beyond $5 \mathrm{~km}$ could not be analysed due to non-availability of observations. $R_{i}^{*}$ profile indicates the atmosphere is unstable from $1.5-4.1 \mathrm{~km}$. The DWR reflectivity at 13:10 UTC of 22 April 2006 is shown in figure 9(a). The maximum reflectivity ranges from 49-60 dBZ with vertical extent up to $14 \mathrm{~km}$. On 30 May 2006, the $R_{i}$ profile shows that the atmosphere is unstable from surface to $6.1 \mathrm{~km} . R_{i}{ }^{*}$ profile shows that 

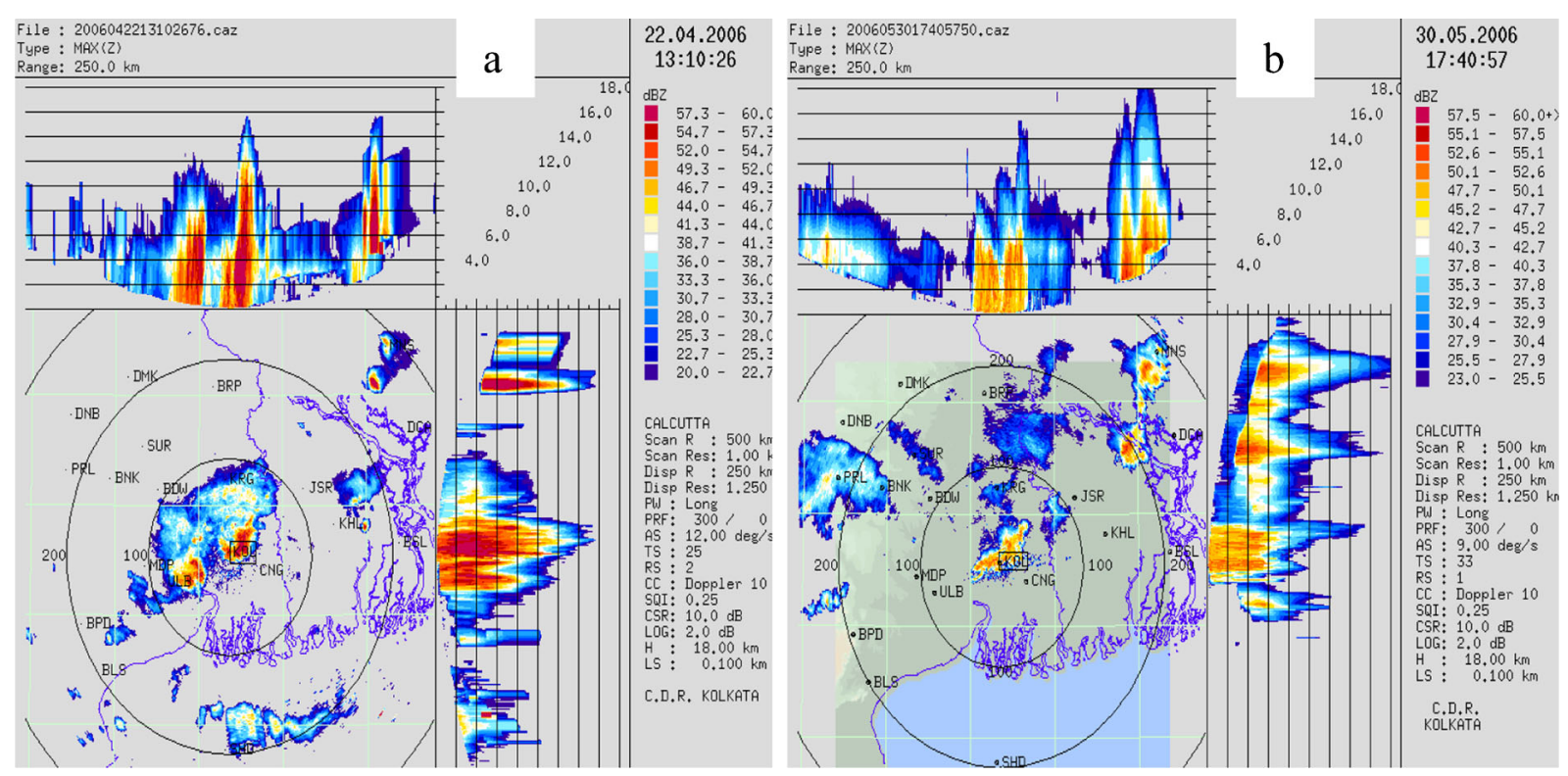

Figure 9. DWR reflectivity (MaxZ) of thunderstorm event (a) at 13.10 UTC on 22 April 2006 and (b) at 17.40 UTC on 30 May 2006 and over Kolkata, India.

0.4-1.2 km layer of atmosphere is unstable and stable above. The sounding available was 5:40 hours before the thunderstorm event and this may be the reason of $R_{i}{ }^{*}$ not representing instability at higher levels. The DWR reflectivity at 17:40 UTC of 30 May 2006 is shown in figure 9(b). The maximum reflectivity ranges from $47-52 \mathrm{dBZ}$ with vertical extent up to $9 \mathrm{~km}$ of the atmosphere. The profile of Richardson number does not indicate higher instability and hence more intense thunderstorms. The heavy precipitation associated with the thunderstorm is perhaps due to the longer persistence of the storm over the region as it was a localized thunderstorm. The $R_{i}$ profile of 10 May 2008, and 26 May 2010 thunderstorm events does not show any significant atmospheric instability (as lowermiddle tropospheric instability was also observed on non-thunderstorm days). The $R_{i}{ }^{*}$ profile of 10 May 2008 and 26 May 2010 shows stable atmosphere with weak instability on 10 May 2008. It may be noted that the thunderstorm occurrence time for the 10 May 2008 and 26 May 2010 cases are at 16:20 and 14:45 UTC, respectively. DWR reflectivity (figure not presented) of 10 May 2008 and 26 May 2010 shows similar features to that of the previous cases. On analysing all the events considered in the study, it is observed that $R_{i}^{*}$ profile few hours before the occurrence of the event is a good indicator of the occurrence of thunderstorms and may be used for now-casting. The $R_{i}$ profile is not a good indicator of severe weather over the region as it shows highly unstable atmosphere in both thunderstorm and non-thunderstorm days.
The Richardson number profile can only indicate the occurrence of thunderstorms. The deeper layer of instability does not ensure occurrence of HP thunderstorms. In the LP thunderstorm cases, the $R_{i}^{*}$ mostly lies in the range of $0-1$ and in case of MP thunderstorms, it is around zero or negative. This indicates that the instability in LP thunderstorm cases is more due to wind shear, whereas the instability in MP thunderstorm cases is due to presence of more moisture and higher temperature.

\subsection{Vertical wind shear}

The Box-and-Whisker diagrams of vertical wind shear (in pre-convective environment) in $0-3,0-6$ and 3-7 km atmospheric layers for thunderstorms with LP, MP and HP are shown in figure 10(a-c), respectively. In more than $75 \% \mathrm{LP}$ thunderstorms, moderate to strong wind shear is observed in the 0-3 km atmospheric layer (figure 10a). Moderate to strong shear in the $0-3 \mathrm{~km}$ atmospheric layer is also observed in more than $70 \%$ MP thunderstorms; whereas in about 50\% HP thunderstorms wind shear is moderate. This indicates that strong pre-convective wind shear in lower troposphere is associated with low precipitation thunderstorms and weak pre-convective wind shear with heavy precipitation thunderstorms. The wind shear in the 0-6 km atmospheric layer shows a similar pattern with moderate to strong shear in more than $75 \%$ LP thunderstorms and more than $70 \%$ MP thunderstorms. Weak wind shear is observed in more than $70 \%$ HP thunderstorms (figure 10b). This indicates that weaker shear in the $0-3$ and $0-6 \mathrm{~km}$ 
layers in the pre-convective environment is associated with thunderstorms leading to more precipitation and stronger shear with thunderstorms leading to less precipitation. The stronger wind shear may be acting like a lid in development of deeper convection, reducing water loading. Figure 10(c) shows that weak to moderate wind shear is observed in the $3-7 \mathrm{~km}$ layer in about 95\% HP thunderstorm cases. The wind shear in the $3-7 \mathrm{~km}$ layer is found to be weak to moderate in $75 \%$ of MP thunderstorms cases and $55 \%$ LP thunderstorm cases. Mean wind shear in the 0-3, 0-6 and 3-7 km atmospheric layers for all three precipitation regimes is shown in table 3 . This shows that the wind shear in the $3-7 \mathrm{~km}$ layer in pre-convective environment is a better predictor of precipitation associated with thunderstorms than that in the $0-3$ and $0-6 \mathrm{~km}$ layers. It is observed that moderate wind shear in the $0-3 \mathrm{~km}$ layer and weak shear in the $0-6$ and $3-7 \mathrm{~km}$ layer in the pre-convective environment leads to thunderstorms with heavy precipitation. The moderate shear in the 0-3 km layer may be helping in the transport of energy and moisture to the subsequent layer of the atmosphere and weak shear there (in 3-7 km layer) favouring the convective development further.

\subsection{Energy helicity index (EHI)}

Box-and-Whiskers diagram of EHI from preconvective sounding of three classified LP, MP and HP thunderstorm days is shown in figure 11(a). It shows that the EHI $\leq 0.39$ for $75 \% \mathrm{HP}, 55 \% \mathrm{MP}$ and $43 \% \mathrm{LP}$ thunderstorms. It can also be seen that higher EHI are associated with lower precipitation thunderstorms and lower EHI are associated with higher precipitation thunderstorms. It indicates that the super-cell thunderstorms that develop over this region are expected to be of low precipitation type. The mean EHI for all three categories of thunderstorms varies significantly as given in table 3 . It may be taken as an important parameter to classify thunderstorms over the region.

\subsection{Vorticity generation parameter (VGP)}

Box-and-Whiskers diagram of VGP obtained from three types of classified thunderstorms is provided in figure 11(b). It shows that the VGP associated with LP thunderstorms is significantly different from VGP of MP and HP thunderstorms. The VGP is more than 0.29 in $75 \% \mathrm{LP}, 37 \% \mathrm{MP}$ and $30 \%$ HP thunderstorms. LP thunderstorm shows more potential of severe weather than MP and HP thunderstorms over the region. VGP classifies well LP, MP and HP thunderstorms. Mean VGP for classified thunderstorms is given in table 3 .
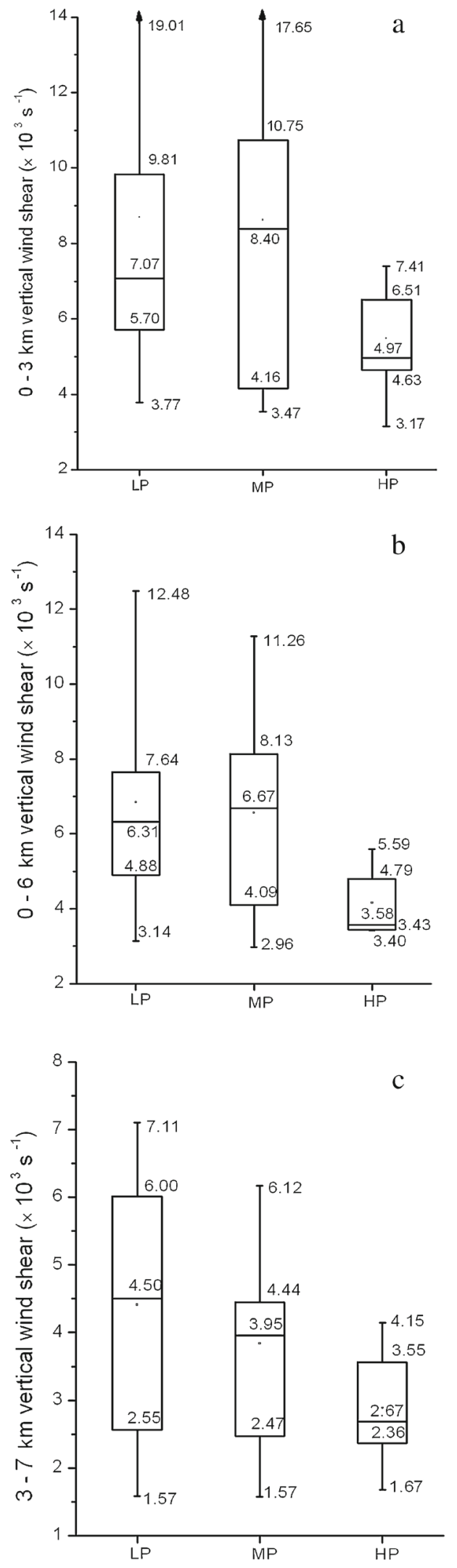

Figure 10. Box-and-Whiskers diagram (a) of $0-3 \mathrm{~km}$, (b) 0-6 km and (c) 3-7 km vertical wind shear of horizontal wind for sounding associated with LP, MP, and HP thunderstorms. The boxes denote 25 th to 75 th percentiles with the middle horizontal bar at the median. The vertical line extends from 5 th to 95 th. 
Table 3. Mean of dynamic/composite parameters in LP, MP and HP thunderstorms.

\begin{tabular}{llll}
\hline & \multicolumn{1}{c}{ LP } & \multicolumn{1}{c}{ MP } & \multicolumn{1}{c}{ HP } \\
\hline 0-3 km shear & $8.71 \times 10^{-3} \mathrm{~s}^{-1}$ & $8.57 \times 10^{-3} \mathrm{~s}^{-1}$ & $5.45 \times 10^{-3} \mathrm{~s}^{-1}$ \\
0-6 km shear & $6.83 \times 10^{-3} \mathrm{~s}^{-1}$ & $6.54 \times 10^{-3} \mathrm{~s}^{-1}$ & $4.15 \times 10^{-3} \mathrm{~s}^{-1}$ \\
3-7 km shear & $4.38 \times 10^{-3} \mathrm{~s}^{-1}$ & $3.82 \times 10^{-3} \mathrm{~s}^{-1}$ & $2.87 \times 10^{-3} \mathrm{~s}^{-1}$ \\
EHI & 1.06 & 0.62 & 0.40 \\
VGP & 0.42 & 0.28 & 0.23 \\
\hline
\end{tabular}
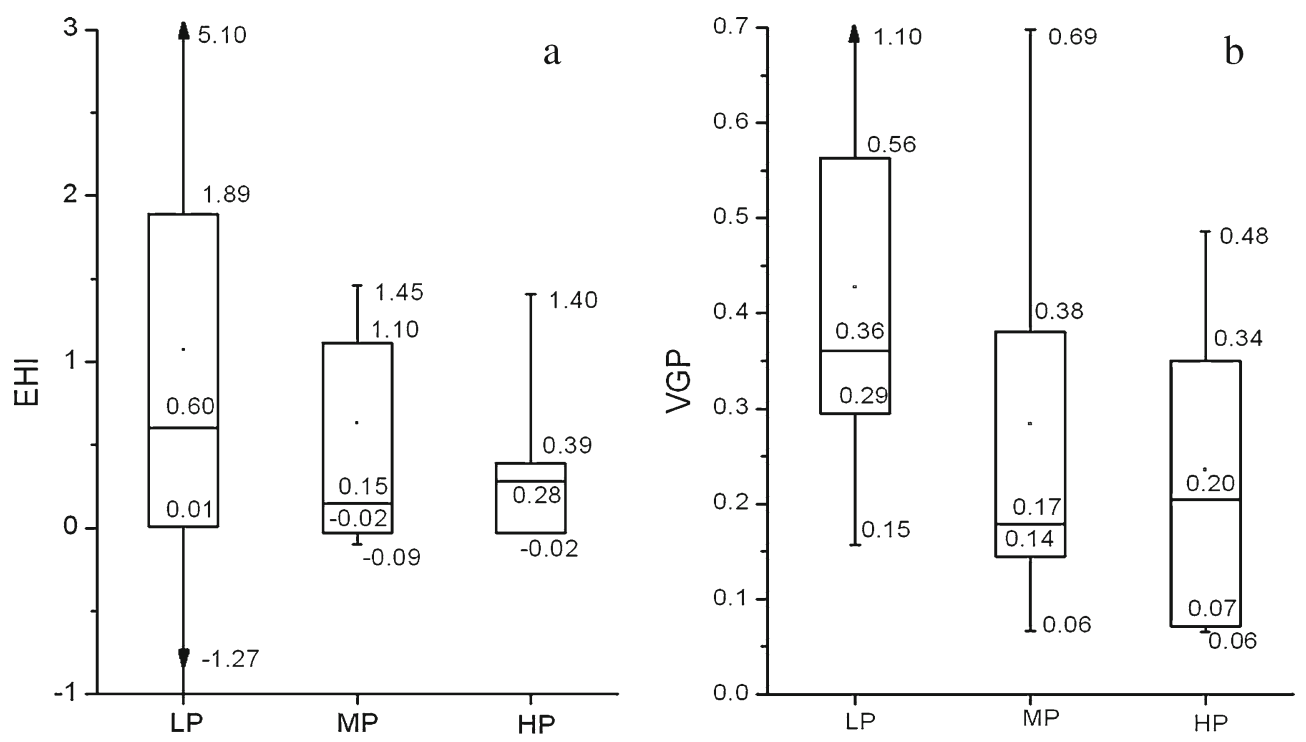

Figure 11. Box-and-Whiskers plot (a) EHI and (b) VGP for sounding associated with three classified LP, MP and HP thunderstorms. The boxes denote same percentile as in figure 10.

\section{Summary and conclusions}

The upper air sounding at 12 UTC over Kolkata during the pre-monsoon period (March-May) of 2005-2012 is used to compute some important dynamical and thermodynamical parameters. The thunderstorms that occurred between 12 and 18 UTC only are considered for the analysis so that the 12 UTC sounding may represent the pre-convective environment over the station. Richardson number in entirely saturated atmosphere and non-uniformly saturated atmosphere $\left(R_{i}\right.$ and $\left.R_{i}{ }^{*}\right)$, vertical wind shear, energy helicity index and vorticity generation parameter are analyzed in relation to three classified (LP, MP, HP) thunderstorms. The analysis of these parameters and related discussion presented in the previous section may be summarized as follows.

Richardson number in non-uniformly saturated atmosphere $\left(R_{i}^{*}\right)$ provides a better measure of instability in pre-convective environment on thunderstorm days than Richardson number in a completely saturated atmosphere $\left(R_{i}\right)$. The instability observed in $R_{i}{ }^{*}$ profile is a good indicator of occurrence of thunderstorms 1-2 $\mathrm{h}$ before the event. In $R_{i}{ }^{*}$ profile, the instabilities are usually observed within the $1.5-4$ and $6-11 \mathrm{~km}$ atmospheric layers. The thick layer of the instability in $R_{i}^{*}$ profile is observed in low precipitation thunderstorms along with heavy precipitation thunderstorms. DWR reflectivity also indicates that presence of deep cloud does not ensure high precipitation thunderstorms. The analysis also infers that the $R_{i}{ }^{*}$ is not very useful in classifying the LP, MP and HP thunderstorms.

Analysis of vertical wind shear in the $0-3,0-6$ and $3-7 \mathrm{~km}$ atmospheric layers indicates that the wind shear in the $3-7 \mathrm{~km}$ layer is a better predictor of precipitation associated with thunderstorms than that in the $0-3$ and $0-6 \mathrm{~km}$ atmospheric layers. Weak shear in $0-3$ and $0-6 \mathrm{~km}$ in the pre-convective environment is associated with thunderstorms leading to more precipitation and strong shear with thunderstorms leading to less precipitation. The stronger wind shear may be acting as a lid in the development of deeper convection, reducing water loading. Moderate wind shear in lower troposphere $(0-3 \mathrm{~km})$ and weak shear in middle troposphere $(3-7 \mathrm{~km})$ leads to heavy precipitation thunderstorms. The moderate shear in the lower troposphere favours the transport of energy and moisture to the subsequent layer of the 
atmosphere and the weak shear in the middle favours the convective development further.

EHI and VGP can well classify the LP, MP, and HP thunderstorms. High EHI are associated with low precipitation thunderstorms and low EHI are associated with heavy precipitation thunderstorms. EHI and VGP also indicate that LP thunderstorm environment is more favourable for severe weather than that of MP and HP thunderstorms.

\section{Acknowledgements}

The Department of Atmospheric Science, University of Wyoming is acknowledged for the Radiosonde data over Kolkata during the premonsoon months of 2005-2012. Weather underground is acknowledged for providing the information regarding the occurrence of thunderstorms and the rainfall datasets. Mr D Pradhan, DDGM, RMC Kolkata is acknowledged for providing the radar imageries over the study area. Department of Science and Technology, Government of India is sincerely acknowledged for providing financial support to conduct the research.

\section{References}

Asai T 1964 Cumulus convection in the atmosphere with vertical wind shear: Numerical experiment; J. Meteorol. Soc. Japan 42 245-259.

Cao J, Zhou Y and Gao S 2011 A brief report of graphic explanations for generalized potential temperature in the non-uniformly saturated atmosphere; Atmos. Ocean. Sci. Lett. 4 162-167.

Chatterjee R N, Prakash P and Singh G 1995 Frequency of thunderstorm occurrence and their height distribution in different regions in India - A radar study Vayu Mandal; J. Indian Meteorol. Soc. 25 41-46.

Chaudhari H S, Sawaisarje G K, Ranalkar M R and Sen P N 2010 Thunderstorms over a tropical Indian station, Minicoy: Role of vertical wind shear; J. Earth Syst. Sci. 119 603-615.

Dalal S, Lohar D, Sarkar S, Sadhukhan I and Debnath G C 2012 Organizational modes of squall -type mesoscale convective system during pre-monsoon season over eastern India; Atmos. Res. 106 120-138.

Davies J M 1993 Hourly helicity, instability, and EHI in forecasting super-cell tornadoes; Preprints, 17th Conference on Severe Local Storms, St. Louis, MO, American Meteorological Soc., pp. 107-111.

Dhawan V B, Tyagi A and Bansal M C 2008 Forecasting of thunderstorms in pre-monsoon season over northwest India; Mausam 59(4) 433-444.

Fankhauser J C 1971 Thunderstorm environment interactions determined from aircraft and radar observations; Mon. Wea. Rev. 99 171-192.

Fankhauser J C 1988 Estimates of precipitation efficiency from field measurements in CCOPE; Mon. Wea. Rev. 116 663-684.

Joseph P V and co-authors 2005 Severe thunderstorms observations and regional modeling (STORM) programme; Science Plan.
Gao S and Cao J 2007 Physical basis of generalized potential temperature and its application to cyclone tracks in nonuniformly saturated atmosphere; J. Geophys. Res. 112 D18101. doi: 10.1029/2007JD008701.

Ghosh A, Lohar D and Das J 2008 Initiation of Nor'wester in relation to mid-upper and low level water vapor patterns on METEOSAT-5 images; Atmos. Res. 87 116-135.

Goa S, Wang X and Zhou Y 2004 Generation of generalized moist potential vorticity in a frictionless and moist adiabatic flow; Geophys. Res. Lett. 31 L12113.

Hart J A and Korotky W 1991 The SHARP workstation v1.50 user guide; National Weather Service, NOAA, US Dept. of Commerce, 30 [available from NWS Eastern Region Headquarters, 630 Johnson Ave, Bohemia, NY 11716].

Koteswaram P and De A C 1959 Study of premonsoon thunderstorms over GWB by radar; Indian J. Meteorol. Geophys. 10 275-282.

Koteswaram P and Srinivasan V 1958 Thunderstorms over Gangetic West Bengal in the premonsoon season and the synoptic factors favorable for their formation; Indian J. Meteorol. Geophys. 9 301-312.

Kunz M 2007 The skill of convective parameters and indices to predict isolated and severe thunderstorms; Natural Hazards Earth Syst. Sci. 7 327-342.

Lohar D and Pal B 1995 The effect of irrigation on premonsoon precipitation over south West Bengal India; J. Climate 8 2567-2570.

Malkus J S 1952 The slopes of cumulus clouds in relation to external wind shear; Quart. J. Roy. Meteorol. Soc. 78 $530-542$.

Mohanty U C et al. 2006 Weather summary during pilot experiment of severe thunderstorms - observations and regional modeling (STORM) programme (13 April to 31 May 2006); Department of Science \& Technology, Government of India, Technology Bhawan, New Delhi.

Mohanty U C et al. 2007 Weather summary during pilot experiment of severe thunderstorms - observations and regional modeling (STORM) programme (13 April to 31 May 2007); Department of Science \& Technology, Government of India, Technology Bhawan, New Delhi.

Mukhopadhyay P, Singh H A K and Singh S S 2005 Two severe Nor'westers in April 2003 over Kolkata using Doppler radar observations and satellite imagery; Weather 60 343-353.

Newton C W and Newton H R 1959 Dynamic interactions between large convective clouds and environment with vertical shear; J. Meteorol. 16 483-496.

Normand C W B 1921 Wet-bulb temperature and thermodynamics of air; India Meteorological Memoirs, 23, Part I.

Rajeevan M, Madhulatha A, Rajasekhar M, Jyoti Bhate, Amit Kesarkar and Appa Rao B V 2012 Development of a perfect prognosis probabilistic model for prediction of lightning over south-east India; J. Earth Syst. Sci. 121(2) 355-371.

Rasmussen E N and Blanchard D O 1998 A baseline climatology of sounding-derived supercell and tornado forecast parameters; Weather Forecast. 13 1148-1164.

Ravi N, Mohanty U C, Madan O P and Paliwal R K 1999 Forecasting of thunderstorms in the pre-monsoon season at Delhi; Meteorol. Appl. 6 29-38.

Robe F R and Emanuel K A 2001 The effect of vertical wind shear on radiative-convective equilibrium states; J. Atmos. Sci. 58 1427-1445.

Sadhukhan I and De U K 1998 Premonsoon convective developments over Gangetic West Bengal during 1980-89; Indian J. Radio Space Phys. 27 102-109. 
Sadhukhan I, Lohar D and Pal D K 2000 Pre-monsoon season rainfall variability over Gangetic West Bengal and its neighborhood; India Int. J. Climatol. 20 1485-1493.

Savvidou K, Orphanou A, Charalambous D, Lingis P and Michaelides S 2010 A statistical analysis of sounding derived indices and parameters for extreme and nonextreme thunderstorm events over Cyprus; Adv. Geosci. 23 79-85.

Schultz P 1989 Relationships of several stability indices to convective weather events in Northeast Colorado; Wea. Forecasting 4 73-80.

Shou S, Li S and Yao X et al. 2003 Mesoscale Meteorology; China Meteorological Press, Beijing. 72p (in Chinese).

Sohoni V V 1928 Thunderstorms of Calcutta (1900-1926); India Meteorological Department Scientific Note 1(3) 25-36.

Srinivasan V K, Ramamuthy Y R and Nene 1973 SummerNor'westers and Andhis and large scale convective activity over peninsula and central parts of the country;
India Meteorological Department, Forecasting Manual Part III.

Tyagi B, Naresh Krishna V and Satyanarayana A N V 2011 Study of thermodynamic indices in forecasting pre-monsoon thunderstorms over Kolkata during STORM pilot phase 2006-2008; Natural Hazards 56 681-698.

Weisman M L and Klemp J B 1982 The dependence of numerically simulated convective storms on vertical shear and buoyancy; Mon. Wea. Rev. 110 504-520.

Weston K J 1972 The dryline of northern India and its role in cumulonimbus convection; Quart. J. Roy. Meteorol. Soc. 98 519-531.

Yang S, Gao S and Wang D 2007 A study of Richardson number and instability in moist saturated flow; Chinese J. Geophys. 50 365-375.

Zhao Y, Cui X and Gao S 2010 Richardson number in a moist atmosphere and its application in the analysis of heavy rainfall events; Acta Meteorologica Sinica $\mathbf{2 4}$ 95-103. 